\title{
USING INCOMPLETE GEOPHYSICAL DATASETS TO MONITOR A CONDUCTIVE GROUNDWATER TRACER EXPERIMENT
}

\author{
Stewart K. Sandberg \\ University of Southern Maine, Geosciences Department \\ 37 College Avenue, Gorham, ME 04038, U.S.A.
}

\begin{abstract}
The tedious and repetative nature of groundwater tracer experiment monitoring using geophysics can result in an incomplete dataset for subsequent interpretation. A fundamental cause is due to the inherent unpredictability of the rate and direction of movement of, and initial geometry of the tracer slug after injection. This problem is inherent to the experiment since if these parameters were accurately known, there would be no need to perform the tracer study. The incompleteness of the geophysical dataset is also directly affected by the balance between collecting enough data to solve the flow problem, and not wanting to collect redundant data due to the high cost of field data acquisition. This paper presents the results of interpreting incomplete geophysical datasets which were obtained to monitor the migration of a conductive saline groundwater tracer through a deltaic sand aquifer in Gray, Maine.

In addition to providing a non-intrusive means for monitoring the temporal movement of the conductive tracer, interpretation of these geophysical data has also yielded a more detailed picture of the geologic and hydrogeologic setting explaining observed anisotropy in flow.
\end{abstract}

\section{INTRODUCTION}

A groundwater tracer test was conducted in a deltaic deposit of fine- to coarse-grained sand in the municipality of Gray, Maine in the summer of 1996. The objective of this test was to determine the velocity (direction and speed) of groundwater flow at the test location. This information was sought to assist the municipality as part of a larger study of groundwater flow initiated to determine the source of volatile organic contamination recently discovered in their water supply wells.

The tracer, consisting of minor amounts of salt mixed with water recovered from each injection point, was injected on July 30, 1996 at two locations 10 meters apart within an abandoned sand pit. One injection was in a groundwater monitoring well screened from 3.4 to $6.4 \mathrm{~m}$ below ground surface, and the other was a surficial injection, within a pit dug into the saturated zone of the aquifer approximately $1 \mathrm{~m}$ below ground surface. Datasets from a variety of geophysical techniques were collected including GPR, terrain conductivity, dipoledipole resistivity and IP, radial array resistivity and IP, Schlumberger array resistivity, misea-la-masse, SP, and TEM.

Previous studies in which conductive tracer tests were monitored using geophysical methods include two papers by White $(1988,1994)$ in which a radial 4-electrode resistivity array, and other resistivity methods, including mise-a-la-masse, were evaluated. The seepage velocity and groundwater flow direction were obtained in these studies from an interpretation 
of the resistivity surveys. Ronning, et.al. (1994) obtained the direction of tracer movement, but had difficulties interpreting data obtained using the pole-dipole electrode configuration.

In this paper, incomplete mise-a-la-masse and radial-array resistivity datasets are analyzed assisted by some results derived from the other methods. Voltage readings, traditionally used alone in mise-a-la-masse, were reduced to apparent resistivity for both methods, eliminating geometric effects of electrode positioning. One-dimensional modeling enhanced resolution by removing the layered-earth effects.

\section{MISE-A-LA-MASSE METHOD}

Perhaps one of the most incomplete datasets collected at the Gray site was data from the mise-a-la-masse method. Mise-a-la-masse data were obtained on only two days, August $2^{\text {nd }}$ and August $9^{\text {th }}$, representing sample times 3 and 10 days after the tracers were introduced, respectively. Figure 1 shows voltages obtained on August $9^{\text {th }}$. One current electrode was placed at $4.6 \mathrm{~m}$ depth in MW-201, and the other was $35.1 \mathrm{~m}$ grid east, $24 \mathrm{~m}$ grid north from the well. Voltages shown were obtained using one stationary potential (reference) electrode at the location shown in the figure, and data were obtained and plotted at the locations along the four traverses, as indicated.

Although data shown in Figure 1 were collected 10 days after the tracers were introduced, there appears to be no indication of them in this type of data display. These data are incomplete mainly because no pre-injection dataset was obtained which could be used for comparison. As a first step in interpretation, each voltage value was converted to an apparent resistivity, thereby accounting for distortions due to the geometry of the array (the reference electrode was not an infinite distance away). If the deltaic deposit hosting the tracer experiment had been a homogeneous halfspace, a simple transformation to apparent resistivity would have delineated the conductive inhomogeneities. However, this was not the case here.

A Schlumberger-array resistivity sounding was completed a short distance away prior to the tracer study, and a layered-earth model was obtained; modeling results are shown in Figure 2. The model boundary at $4.2 \mathrm{~m}$ depth matches lithology in MW-201 which indicates a boundary at $3.1 \mathrm{~m}$ between overlying medium to coarse sand and fine sand below (the 1.1

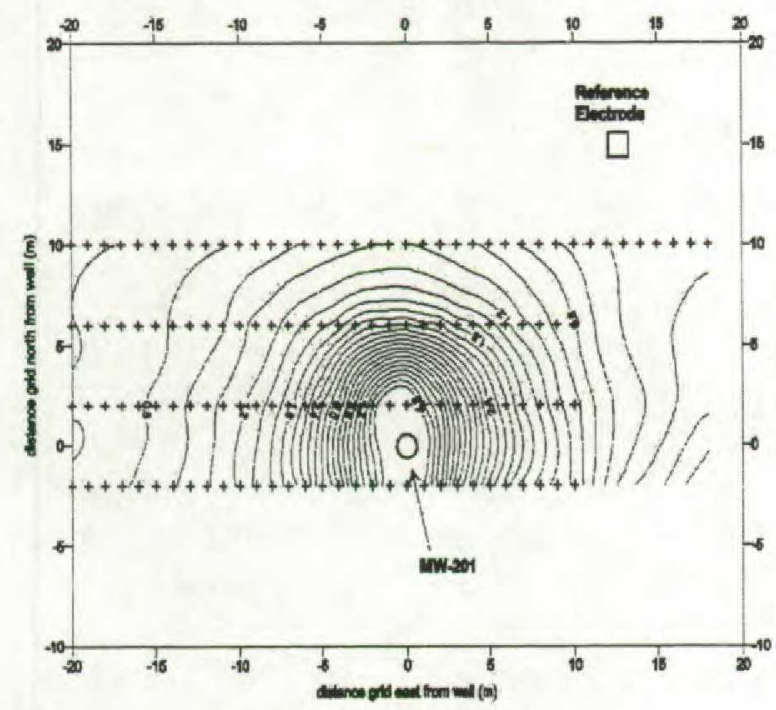

Figure 1.

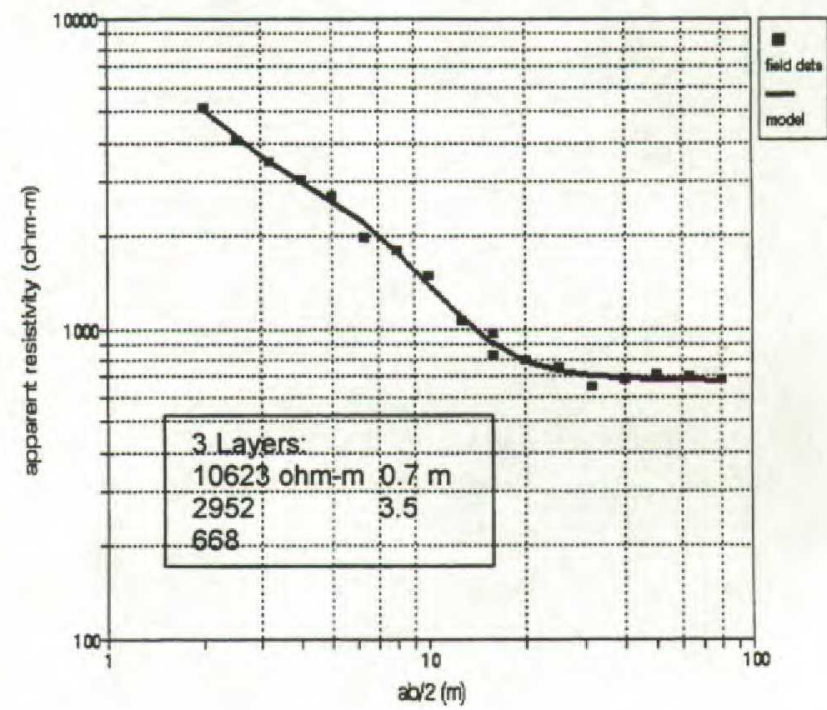

Figure 2.

$\mathrm{m}$ difference likely arising from thickness variation from the well to where the sounding was obtained). Based on this lithological/electrical resistivity boundary, a two-layered earth 
model was obtained by forward modeling data from the mise-a-la-masse traverse $10 \mathrm{~m}$ north of the well (Figure 1). This model consisted of an $800 \mathrm{ohm}-\mathrm{m}$ layer $3 \mathrm{~m}$ thick overlying a 440 ohm-m layer. Data from this model was used as a background dataset for interpretation of the mise-a-la-masse field data.

Figure 3 shows data from the line located $6 \mathrm{~m}$ grid north of MW-201. Also shown in the figure are calculated data from the two-layered earth model, and a residual obtained by direct subtraction of the model data from the field data. Note the anomaly low at station -11 $\mathrm{m}$, and the broad low from stations -4 to $+3 \mathrm{~m}$. The misfit between model-derived and field data for large negative numbered stations is due to a breakdown in the layered-earth

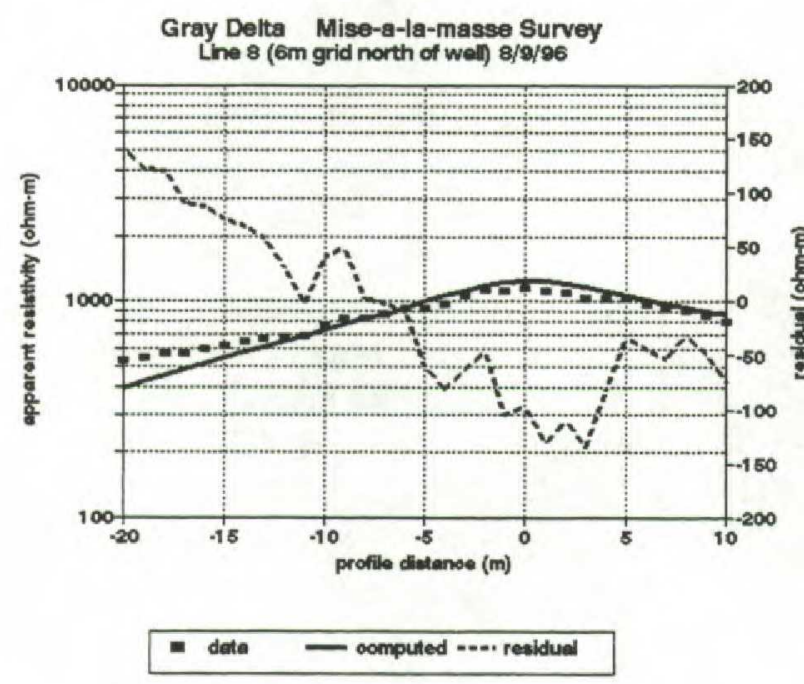

Figure 3.

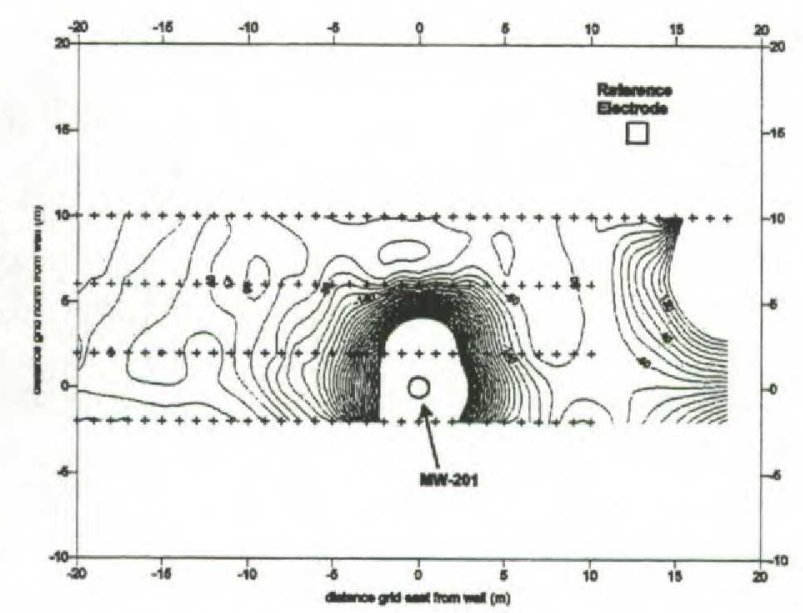

Figure 4.

assumption for the background. The deltaic sand host varies laterally in resistivity, following variations in lithology due to depositional inhomogeneity.

Figure 4 shows a contour map of residual resistivity, obtained through a direct subtraction of model-derived data from the field data. The disruption in contours near $-10 \mathrm{~m}$ on lines 2 and $6 \mathrm{~m}$ north is due to the conductive tracer which has migrated grid north, down gradient from the injection point at 0 north, -10 east. The large negative values near the well

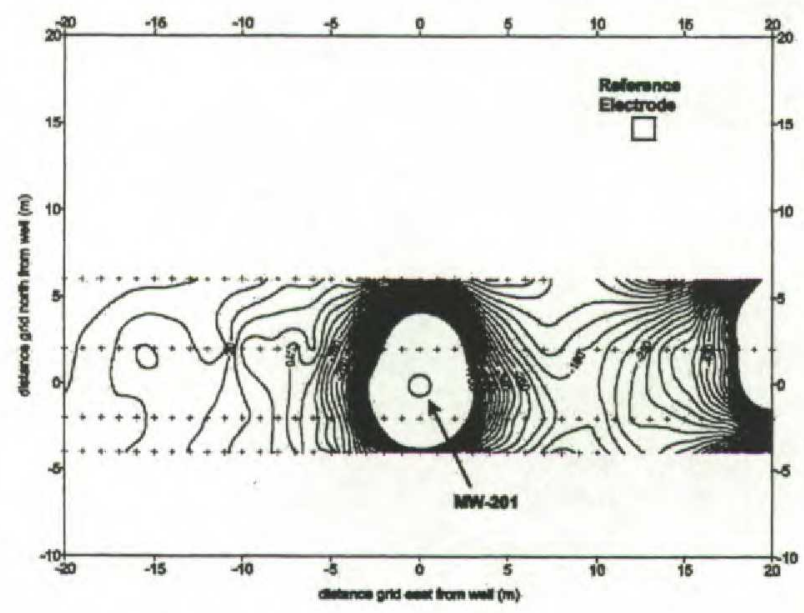

Figure 5.

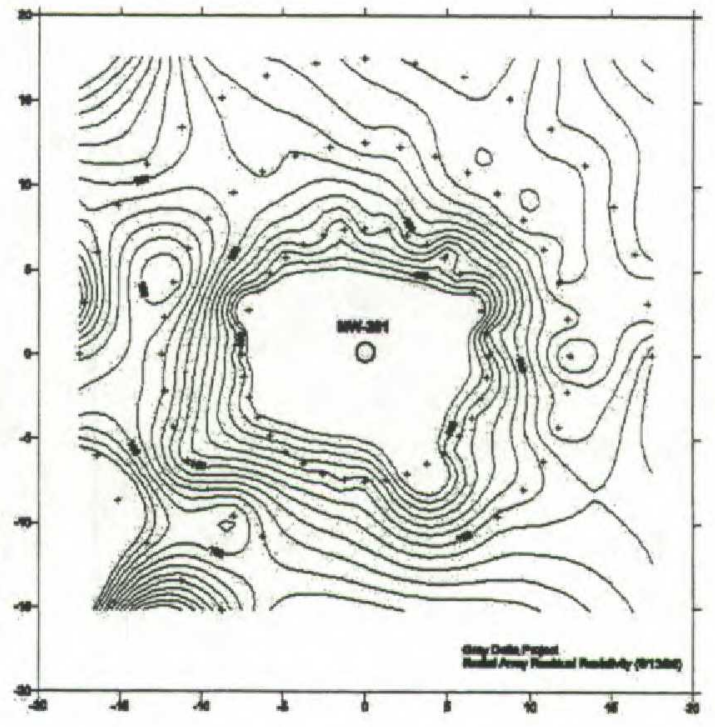

Figure 6. 
are due to using a forward modeling algorithm which assumed the current electrode at the well was at the surface, not at the actual $4.6 \mathrm{~m}$ depth.

For comparison, Figure 5 shows the residual resistivity for the August $2^{\text {nd }}$ dataset. Although this dataset shows some different lines than the August $9^{\text {th }}$ dataset, disruption of the contours, indicating the presence of the tracer, is confined to the $2 \mathrm{~m}$ north line at -10 east. Data from the $6 \mathrm{~m}$ north line for August $2^{\text {nd }}$ (not shown) can be directly compared to Figure 3 , showing data obtained 7 days later. The anomaly low at $-11 \mathrm{~m}$ and the broad low from stations -4 to $+3 \mathrm{~m}$ in Figure 3 are therefore anomalies caused by the two tracers, the movement of which can be observed by comparison with Figure 5 .

\section{RADIAL RESISTIVITY ARRAY METHOD}

Radial array resistivity data were collected on lines oriented in a radial pattern away from MW-201. The array is a modified pole-dipole array in which a current electrode is located $4.6 \mathrm{~m}$ down the well, and potential electrodes are at an a-spacing of $5 \mathrm{~m}$ (dipole length) with $n$ (number of dipole distances away from the well) ranging from 1 to 5 . The dataset is incomplete since no pre-injection data were obtained for this method.

Figure 6 shows radial array apparent resistivity residual data obtained on August $13^{\text {th }}$. Using the same model as for the mise-a-la-masse correction described above, Figure 6 was constructed using residual resistivities obtained by subtracting the model-derived values from the field data. Note that this technique has resulted in bringing out the expression of the tracer located near $-10 \mathrm{~m}$ east, $5 \mathrm{~m}$ north. The tracer injected into the well is not observable in this residual plot, however, most likely due to the depth of the injection and the geometry of the array. Using the same direct subtaction technique, data (not shown) from September $20^{\text {th }}$ does show the tracer injected into the well.

\section{CONCLUSIONS}

In this paper, incomplete resistivity datasets obtained to monitor a conductive groundwater tracer experiment are interpreted. Results are shown in which the simple subtraction of a layered-earth response from resistivity field data was effective in delineating the groundwater tracer. These datasets were incomplete, in that there was no background, or preinjection data available.

\section{REFERENCES}

Ronning, J. S., Morris, M., Kitterod, N. O., and Lile, O. B., 1994, Monitoring of a tracer experiment with electrical resistivity at Haslemoen, Hedmark County, Norway: Proceedings of the Symposium on the Application of Geophysics to Engineering and Environmental Problems, p. 675-688.

White, P. A., 1988, Measurement of ground-water parameters using salt-water injection and surface resistivity: Ground Water, vol. 26, no. 2, p. 179-186.

White, P. A., 1994, Electrode arrays for measuring groundwater flow direction and velocity: Geophysics, vol. 59, no. 2, p. 192-201. 